\title{
UPGRADING COMPETENCIES OF MASTER'S DEGREE STUDENTS THROUGH E-LEARNING IN BUSINESS COMMUNICATIONS IN A FOREIGN LANGUAGE
}

\author{
Andrey Zahariev ${ }^{1 *}$, Margarita Mihailova ${ }^{2}$, Viktor Monev ${ }^{3}$ and Ventsislav Dikov ${ }^{4}$ \\ ${ }^{1}$ Prof. Dr., D. A. Tsenov Academy of Economics, Svishtov, Bulgaria, \\ andrey.zahariev.1971@gmail.com \\ 2Sen. lect. Dr., D. A. Tsenov Academy of Economics, Svishtov, Bulgaria,m.mihaylova@uni- \\ svishtov.bg \\ ${ }^{3}$ Sen. lect. Dr., D. A. Tsenov Academy of Economics, Svishtov, Bulgaria, v.monev@uni-svishtov.bg \\ ${ }^{4}$ Sen. lect., D. A. Tsenov Academy of Economics, Svishtov, Bulgaria, v.dikov@uni-svishtov.bg \\ ${ }^{*}$ Corresponding author
}

\begin{abstract}
The role of foreign language proficiency in modern society, where phenomena such as the Internet remove traditional barriers to human communication, has become increasingly important, which places ever higher demands on the results from foreign language teaching. The process of globalization has increasingly imposed the need for communicative competence and understanding of the culture of nations that use a foreign language, requires the development of not only language skills in learners, but also of critical thinking, soft skills and social responsibility. In this light, the paper aims to present the experience of one of the schools that are benchmark institutions of the higher educational system of Republic of Bulgaria - D. A. Tsenov Academy of Economics - Svishtov in further development of foreign language competencies through master degree e-learning courses in business communications. It covers the evolution of the master's degree in social science with business communications training in a foreign language over the past 20 years reaching peak level of over 2,500 students on annual basis and covering $100 \%$ of the master degree students. The foundations of distance learning of foreign languages at the observed Academy were laid in the period 2001 - 2003 with two pilot courses: "Business Communications in English" and "Business Communications in German". These courses were included as optional elective courses for students from all master degree programs at D. A. Tsenov Academy of Economics - Svishtov. In the next academic years, the courses were revised and upgraded and a number of opportunities for the customization of the instruction to tap the potential of the students were identified. In the 2008/2009 academic year the leading for Bulgaria in the field of distance learning higher school D. A. Tsenov Academy of Economics - Svishtov included the Web-based courses in Business Communications as compulsory elective optional foreign language courses in the curriculum of its master degree programmes. The courses were developed in English, German, French and Russian (levels A2 and B1). The responsibility for their organization was shared by the Center for Postgraduate Training, the Center for Distance Learning and the Department of Foreign Languages. The courses were compulsory for all master degree students of D. A. Tsenov Academy of Economics - Svishtov. They added to the competiveness of all graduates through training and self-assessment using a languagebased portfolio of business communication competencies. The learning content of the Business Communications in Foreign Language courses was provided through the BCom learning platform (a customized Moodle platform) that ensured a higher level of interactivity for the specific objectives of the courses. The specific features of e-language learning provides ways to meet students' needs, which in comparison with traditional learning, are consistent with the characteristics of modern e-society. This
\end{abstract}


reformulates the status and the role of the instructor and the learner within an online community working towards common educational goals. The main content of the courses follows a syllabus that includes the following topics: Economic trend; Business communication; Corporate identity; HR management; EBusiness; Finance; Banking; International marketing; Audit; and International negotiations and contracting. Although the authors put emphasis on vocabulary practice, reading and writing tasks, and listening activities, it is not a purely language course but a business communications one. Logically, at the peak load of the distance learning system for the first decade of the 21st century (in 2009) in D. A. Tsenov Academy of Economics - Svishtov, the e-learning traffic data reached 102 thousand unique logs from abroad (localized by IP addresses) - 41 countries on 6 continents. In the second decade, a peak was registered in 2013 with logs of master degree students from abroad, including 128 countries and 262 thousand unique logs by IP address. In both peak cases, the total number of master degree students was over 2,500 trainees on an annual basis. All this logically confirms that the internationalization of the portfolio of educational products in higher education is the basis for attracting students and ensuring the convergence of diplomas and knowledge. In 2013 , the courses became optional and the number of students rapidly decreased due to the associated additional tuition costs. However, the established methodology and procedures were a solid base for development and introduction of a distance learning course at advanced level (C1) (Advanced Business English) for the Bachelor's Degree programmes taught in English. Nowadays the course aims to revise and consolidate the knowledge that students already have (they are required to have at least a B1 level to enrol in these programmes) and to upgrade their general and professional communication skills to level $\mathrm{C} 1$ and beyond. Since such an upgrade requires many class hours, the course was subdivided into four modules taught within four consecutive semesters of 14 weeks each. The first two modules are more intensive (with 4 class period per week or a total of 56 classes per semester) because they are intended to develop further the language knowledge and skills acquired during secondary education. Modules 3 and 4 are more skillsoriented and therefore require less in-class interaction and considerably more self-study. The study load for these modules is 2 classes per week, or a total of 28 classes per semester. The main conclusion of the study is that BCom business communication courses are a key element in the education of students in social sciences, based on the classic three pillars for a successful career - digital competence, foreign language skills and high competence in the subject areas studied in the bachelor's and master's degree programmes.

Keywords: E-learning, Business Communications, Master's Degree in Social Science

\section{INTRODUCTION}

Education in the social sciences is based on the perception of society as a single value system with diversity in its elements. Internationally, linguistic diversity is both a barrier and an opportunity. Native languages give national identity. They give the opportunity to communicate on the area of land within the national borders, but often hamper the communication between people from different countries. It is the proficiency in a foreign language that broadens the horizons and creates opportunities for both individuals and businesses. Similarly to the world of money and monetary relations where there are established reserve currencies, in the linguistic diversity there are leading languages in which the content of trade contracts is drawn up, invoices are issued, transfers between bank accounts are ordered. That is why the integrity between language learning and career is so desired and purposefully cultivated in individual education systems and universities.

The role of foreign language proficiency in modern society, where phenomena such as the Internet remove traditional barriers to human communication, has become increasingly important. This places ever higher demands on the results from foreign language teaching. The process of globalization has increasingly imposed the need for communicative competence and understanding of the culture of nations that use a foreign language, requires the development of not only language skills in learners, but also of critical thinking, soft skills and social responsibility. In this light, the paper aims to present the experience of one of the schools that are part of the higher educational system of Republic of Bulgaria - D. A. Tsenov Academy of Economics - Svishtov in further development of foreign language competencies through master's degree e-learning courses in business communications. It covers the evolution of the master's degree in social science with business communications training in a foreign language over the past 20 years reaching a peak level of over 2,500 students on annual basis and covering $100 \%$ of the master degree students. 


\section{PHILOSOPHY OF THE BUSINESS COMMUNICATION TRAINING IN A FOREIGHN LANGUAGE}

\subsection{Fundamentals of Business Communications and CEFR levels}

Business communications (BCom) are based on two key points: first, the use of language as a means of oral and written communication and the use of specific code containing terminology in a professional field, etiquette in establishing contacts and knowledge about the subject of the transaction. There are different scales for assessing the level of proficiency in a language; the widely used in the European Union are used the Common European Framework of Reference for Languages (Common European Framework of Reference for Languages, Council of Europe) and the ALTE scale. The common reference language framework comprises 3 levels (A, B, C) with two sub-levels in each; ALTE uses five levels (ALTE Framework). What these scales have in common is that as the level of language competence increases, the ability of communicators to communicate grows. BCom business communication courses cover the middle zone (A2-B in the mass profile of trainees, the so-called Independent User) and level C (for outstanding students, Proficient User) according to the Common Reference Language Framework.

Table 1. Scales for assessing the level of foreign language proficiency

\begin{tabular}{|c|c|c|c|c|c|}
\hline \multicolumn{6}{|c|}{ Common European Framework of Reference } \\
\hline \multicolumn{2}{|c|}{ Level A> Basic User } & \multicolumn{2}{|c|}{ Level B> Independent User } & \multicolumn{2}{|c|}{ Level C> Proficient User } \\
\hline A1 & $\mathrm{A} 2$ & B1 & B2 & $\mathrm{C} 1$ & $\mathrm{C} 2$ \\
\hline \multicolumn{6}{|c|}{ Association of Language Testers in Europe } \\
\hline Breakthrough & ALTE Level 1 & ALTE Level 2 & ALTE Level 3 & ALTE LEVEL 4 & ALTE Level 5 \\
\hline
\end{tabular}

Source: (Common European Framework of Reference for Languages (CEFR), 2021)

The choice of languages in BCom is based on several factors:

- globalization and the need to communicate with business partners from around the world,

- multilingualism within the European Union,

- the relatively high weight of a small number of languages in international communications.

\subsubsection{The language distribution in the EU and profiling of educational products}

Globally, there has always been a need to use the same language in personal and business communication. During the Roman Empire, such a common language was Latin, which retained its position until the late Middle Ages; in more recent times, French established itself as the language of diplomacy and culture. In the twentieth century, English became the language of global communication. This has required the priority inclusion of business English in BCom. The presence of other languages (French, Russian and German) is determined by both the traditions in the Bulgarian school educational system and the relatively high weight of French in Western Europe, German in Central and Eastern Europe and Russian in Eastern Europe and the countries of the former Soviet Union bloc. A Eurobarometer survey shows the following prevalence of some widespread languages in the European Union with the leading position of English (See Table 2 and Table 3).

Table 2. Distribution of the answers according to the question "Languages that you speak well enough in order to be able to have a conversation - TOTAL?" in 2021 survey of Eurobarometer 386

\begin{tabular}{|l|c|c|c|c|c|c|c|c|c|c|c|c|}
\hline & EU6 & EU9 & EU10 & EU12 & $\begin{array}{c}\text { FI/ } \\
\text { AT } \\
\text { SE }\end{array}$ & EU15 & $\begin{array}{c}\text { EURO } \\
\text { ZONE }\end{array}$ & $\begin{array}{c}\text { NON } \\
\text { EURO }\end{array}$ & NMS10 & NMS12 & EU25 & EU27 \\
\hline English & $48 \%$ & $40 \%$ & $40 \%$ & $38 \%$ & $78 \%$ & $40 \%$ & $44 \%$ & $28 \%$ & $32 \%$ & $32 \%$ & $39 \%$ & $38 \%$ \\
\hline
\end{tabular}


Proceedings of SOCIOINT 2021 8th International Conference on Education and Education of Social Sciences 14-15 June, 2021

\begin{tabular}{|l|r|r|r|r|r|r|r|r|r|r|r|r|}
\hline French & $15 \%$ & $16 \%$ & $16 \%$ & $14 \%$ & $9 \%$ & $14 \%$ & $13 \%$ & $11 \%$ & $3 \%$ & $6 \%$ & $12 \%$ & $12 \%$ \\
\hline German & $14 \%$ & $12 \%$ & $12 \%$ & $10 \%$ & $17 \%$ & $10 \%$ & $11 \%$ & $13 \%$ & $18 \%$ & $15 \%$ & $12 \%$ & $11 \%$ \\
\hline Russian & $1 \%$ & $1 \%$ & $1 \%$ & $2 \%$ & $1 \%$ & $2 \%$ & $2 \%$ & $9 \%$ & $19 \%$ & $16 \%$ & $4 \%$ & $5 \%$ \\
\hline Other & $21 \%$ & $15 \%$ & $15 \%$ & $12 \%$ & $23 \%$ & $12 \%$ & $14 \%$ & $11 \%$ & $16 \%$ & $16 \%$ & $13 \%$ & $12 \%$ \\
\hline None & $43 \%$ & $46 \%$ & $46 \%$ & $48 \%$ & $18 \%$ & $46 \%$ & $44 \%$ & $50 \%$ & $44 \%$ & $47 \%$ & $46 \%$ & $46 \%$ \\
\hline
\end{tabular}

Source: Special Eurobarometer 386: Europeans and their Languages (Eurobarometar, 2021)

Table 3. Distribution of the answers to the question "Which first other language, if any, do you speak well enough in order to be able to have a conversation?" in 2021 survey of Eurobarometer 386

\begin{tabular}{|l|r|r|r|r|r|r|r|r|r|r|r|r|}
\hline & EU6 & EU9 & EU10 & EU12 & $\begin{array}{r}\text { FI/ } \\
\text { AT } \\
\text { ISE }\end{array}$ & EU15 & $\begin{array}{r}\text { EURO } \\
\text { ZONE }\end{array}$ & $\begin{array}{r}\text { NON } \\
\text { EURO }\end{array}$ & NMS10 & NMS12 & EU25 & EU27 \\
\hline English & $40 \%$ & $34 \%$ & $34 \%$ & $31 \%$ & $71 \%$ & $34 \%$ & $36 \%$ & $24 \%$ & $25 \%$ & $25 \%$ & $32 \%$ & $32 \%$ \\
\hline French & $5 \%$ & $7 \%$ & $7 \%$ & $6 \%$ & $1 \%$ & $6 \%$ & $4 \%$ & $7 \%$ & $1 \%$ & $2 \%$ & $5 \%$ & $5 \%$ \\
\hline German & $6 \%$ & $5 \%$ & $5 \%$ & $4 \%$ & $3 \%$ & $4 \%$ & $5 \%$ & $5 \%$ & $9 \%$ & $7 \%$ & $5 \%$ & $5 \%$ \\
\hline Other & $6 \%$ & $8 \%$ & $8 \%$ & $11 \%$ & $7 \%$ & $10 \%$ & $11 \%$ & $14 \%$ & $20 \%$ & $19 \%$ & $12 \%$ & $12 \%$ \\
\hline None & $43 \%$ & $46 \%$ & $46 \%$ & $48 \%$ & $18 \%$ & $46 \%$ & $44 \%$ & $50 \%$ & $45 \%$ & $47 \%$ & $46 \%$ & $46 \%$ \\
\hline
\end{tabular}

Source: Special Eurobarometer 386: Europeans and their Languages (Eurobarometar, 2021)

The distribution of the answers from the latest survey from 2021 of Eurobarometer 386 confirms the leading position of the English language regardless of Brexit. Therefore, the innovative course in business communications for students of social sciences and economics (BCom) is a kind of a response to the process of globalization. BCom is characterized by the general thematic structure for the four languages and the adherence to the set language levels. The individual language courses use lexical, grammatical and communicative exercises, which aim at the complex development of the communicative competence of the students to be used in business situations. In the process of creating the courses, a revolutionary concept for Internet-based distance learning has been applied, taking advantage of modern information technology. The course team have created an interactive environment for asynchronous learning, which allows for intensive training of language structures, communication situations, case studies, collection of economic information, presentation of summarized results and more. A similar type of learning, using distance learning tools, is presented in a Marwan Elmubarak study on project-based learning (Elmubarak, 2020, pp. 357-364) and the various studies of practical-orientated concept of professional education (Diachok, Chernukha, Tokaruk, Udovenko, \& Petrova, 2020, pp. 272-282) and training of economic sector specialists (Zagorodnya, et al., 2020, pp. 139-144)

\subsubsection{The historical development of BCom in the Bulgarian higher education institutions}

The innovative course in business communications in a foreign language is based on modern interactive Internet technologies and provides for flexible development of foreign language skills in the professional business sphere. The learning content is structured in texts and self-study tasks, various lexical and grammatical exercises, online tests, a semester case study with a practical focus and additional multimedia resources available from a specialized website.

The foundations of distance learning of foreign languages were laid in a benchmark higher educational institution in Bulgaria - D. A. Tsenov Academy of Economics, Svishtov, in the period $2001-2003$ with two 
pilot courses: "Business Communications in English" and "Business Communications in German". These courses were offered as optional elective courses for students in all master's degree programmes at D. A. Tsenov Academy of Economics - Svishtov. In the following academic years, the courses were revised and upgraded to include a number of options for student-centered customization. These new features included individual assignments and collaborative tasks, standardization of instruction; a more objective and flexible assessment process; opportunities for subsequent diversification of self-study didactic materials; content and language integrated learning (CLIL).

In the 2008/2009 academic year, as a leader in the field of distance learning in Bulgaria, D. A. Tsenov Academy of Economics included the Web-based courses in Business Communications in English, German, French and Russian at levels A2 and B1 according to the CEFR as compulsory elective foreign language courses in all master's degree curricula. The responsibility for their organization was shared by the Center for Postgraduate Training, the Center for Distance Learning and the Department of Foreign Language Teaching. The learning content of the Business Communications in Foreign Language courses was provided through the BCom(c) learning platform (a customized Moodle platform) that ensured a higher level of interactivity for the specific objectives of the courses.

The specific features of e-language learning provides ways to meet students' needs, which in comparison with traditional learning, are consistent with the characteristics of modern e-society. This reformulates the status and the role of the instructor and the learner within an online community working towards common educational goals. The main content of the courses follows a syllabus that includes the following topics: Economic trend; Business communication; Corporate identity; HR management; E-Business; Finance; Banking; International marketing; Audit; and International negotiations and contracting. The philosophy is to cover main business activities and branches of the economy (Terziev, 2019, pp. 324-330) based of the open economy and labour market demand (Terziev \& Ivanov, 2020, pp. 6-13) for staff with international economic relations education competence (Nenkov, Dyachenko, Petrova, Bondarenko, \& Pustovit, 2017, pp. 353-360)

Although the authors put emphasis on vocabulary practice, reading and writing tasks, and listening activities, it is not a purely language course but a business communications one. The course reviews a set of grammar categories which master's degree students have presumably mastered during their studies so far and aims to expand further their business-related vocabulary. Moreover, as not only grammar and lexical proficiency are indicative of students' progress, their ability to cope with practical everyday business tasks (e.g., composing or replying to a business letter, searching for and analysing available economic data, etc.) are also assessed and included in the final achievement.

With the introduction of BCom courses on an internal project of the benchmark institution, a comparative study of ICT-based and conventional methods for testing the knowledge and skills of students was conducted. The project sought answers to some of the following questions: What is the degree of correspondence between online and conventional tests?; What are the structural features of online tests?; What are the advantages and disadvantages of online tests compared to conventional ones?; What is the degree of applicability of online tests in specialized foreign language teaching?

The object of the survey was to compare the achievement of the students at didactic tests used to check and assess the knowledge and language skills of students of economics in higher education depending on the form of the test - on paper or electronically. For the purposes of the research the authors of the BCom courses generated in the Moodle e-learning system tests comprised of tasks of the types free answer tasks, mixed tasks, and structured answer tasks. As the statistical analysis of the scattering of the achieved results did not reveal significant differences between the two versions of the test (paper and electronic), it was concluded that both forms of testing can be used equally in the process of learning a foreign language, but the innovative format has undeniable advantages in a purely practical aspect.

On that basis the e-learning approach of testing of BCom students was widely introduced. At the peak load of the distance learning system for the first decade of the 21st century (in 2009), the e-learning traffic data reached 102 thousand unique logs from abroad (localized by IP addresses) - 41 countries on 6 continents. In the second decade, a peak was registered in 2013 with logs of master's degree students from 128 countries around the world with 262 thousand unique logs by IP address. In 2013, the courses became optional and the number of students rapidly decreased due to the associated additional tuition costs. However, the established methodology and procedures were a solid base for the development and the introduction of a distance learning course at advanced level (C1) (Advanced Business English) for the bachelor's degree programmes taught in English. 


\subsection{From specialized one year language product towards widespread multiyear and multilevel BCom studying}

At present the course aims to revise and consolidate the knowledge that students already have (they are required to have at least a $\mathrm{B} 1$ level to enrol in these programmes) and to upgrade their general and professional communication skills to level $\mathrm{C} 1$ and beyond. Since such an upgrade requires many class hours, the course was subdivided into four modules taught within four consecutive semesters of 14 weeks each. The first two modules are more intensive (with four class period per week, or a total of 56 classes per semester) because they aim to develop further the language knowledge and skills acquired during secondary education. Modules 3 and 4 are more skills-oriented and therefore require less in-class interaction and considerably more self-study. The study load for these modules is two classes per week, or a total of 28 classes per semester. The specific learning objectives and outcomes for each module are summarized below:

MODULE 1: As economic theories are a fundamental part of every economic thinking, Module I is devoted to the most influential thinkers of the past and the present day and the fundamental ideas they proposed. The course also revises and consolidates some of the main grammar topics such as the English tense system, the various types of verb forms, etc. The aim of this course is to provide the students with the knowledge, language skills and competences they will find useful in their future business careers. This includes competent use of specialized terminology; working with specialized texts and documents in English; handling correspondence with partners and clients; engaging in verbal communication - giving presentations, participating in dialogues and discussions; retrieving information from messages, news, reports, interviews, etc., and reading comprehension of specialized literature and working with internet sources. Upon completion of the course, the students must be able to work with specialised texts and documents in English; comprehend and compose business letters; participate in business discussions in English; to read and analyse specialized texts in English in the field of Economics.

MODULE 2: Module II of the course presents some issues pertinent to financial markets, globalization and business ethics. On the practical side students also learn/review how to read and interpret financial statements, which is a key to analysing the financial position of a company. It also revises and consolidates their knowledge on some grammar topics.

MODULE 3: Module III of the course is devoted to the topics of risk, insurance and reinsurance, global marketing, management styles and employment. The course continues the grammar revision and practice and develops further the written and oral production skills of the students putting and emphasis on the stylistic and structural conventions of academic writing and public speaking.

MODULE 4: Module IV of the course is devoted to the topics of cultural differences, social responsibility and business ethics. On the more practical side, it covers some issues related to raising finance and negotiating. Having revised and consolidated your grammar knowledge, it focuses on writing emails, proposals, reports and academic essays.

\subsection{The E-learning environment and the individual approach of the business communication training in a foreign language}

The role of foreign language proficiency in modern society, where phenomena such as the Internet remove traditional barriers to human communication, is becoming increasingly important, which places ever higher demands on the effectiveness of their study. The process of globalization increasingly imposes the need for communicative competence and understanding of the culture of nations that use the studied foreign language, requires the development of not only language skills in learners, but also critical thinking, social skills and civic responsibility in them. Changes in learners' needs will inevitably lead to changes in their motivation, and the role of motivation in foreign language learning is a key success factor. The motivation to learn a foreign language is influenced not only by the language needs, but also by the life needs of the particular learner. Given the predominantly instrumental motivation to learn a foreign language in Bulgaria, learning management systems provide various opportunities to apply modern techniques and strategies to encourage increased integrative motivation in learning a foreign language. In practice, it is difficult to identify a direct link between the level of motivation to learn a foreign language and the level of language competence of learners, except in terms of their participation in various forms of web communication. The latter could be attributed to a higher level of language anxiety.

E-language learning meets not only the higher needs of the learner for self-improvement and realization of their own abilities, but also the needs for self-esteem, respect and approval, through the ability to choose 
materials and learning strategies and the ability to compare with the other participants in the learning process. The importance of the high level of motivation that all learners would like to achieve in their learners is closely related to the need for achievement. In this aspect, the timely and adequate feedback between the purposeful actions, the quality and the peculiarities of the obtained results is of utmost importance for the quality and efficiency of the learning process, as it provides information to the learners about the degree of achievement of the pre-formulated goals and the success and progress achieved. E-learning allows automation of a large part of the feedback process, which leads to optimization of the learning process. Communication can take place in a foreign language, which, if used skilfully by the teacher, can reduce language anxiety.

E-learning also satisfies the need of the learners to belong to a certain social group and to create social contacts, through the constant connection with the other learners and teachers. The high level of motivation is extremely important for foreign language learning due to the strong communicative aspect of its goals. In the absence of active communication between the teacher and the students, the effectiveness of foreign language teaching decreases significantly and to a much higher degree than in other academic fields (Zahariev, 2009, pp. 5-7). Due to the physical distance between the teacher and the learners and the limited opportunities for non-verbal communication, E-learning and in particular distance foreign language learning must be aimed at creating group affiliation and encouraging contacts between all participants in the learning process. One of the essential elements in this aspect is the creation of an online community, which must bear the characteristics of this type of community in a humanized environment, with different moderation and different written and unwritten rules.

Thirdly, the possibility to choose a place of study, as well as the greater availability of help from the teacher and other learners create in the learner a sense of protection from fear and inconvenience, forms in him the feeling that the learning process in it is largely under his control compared to traditional forms of education. What is specific about foreign language learning compared to other academic fields is that the learner is constantly required to communicate through a tool that he does not master perfectly, which provokes the creation of insecurity and fear that he will not be able to build an image that meets of its true nature. The learning content of the course, designed for learners with a lower level of language proficiency, should be in line with their relatively limited vocabulary, as frequent exposure to a situation in which the learner cannot effectively communicate or understand what is read or heard, leads to lower confidence and demotivation.

Another interesting aspect in this direction is the need for autonomy. In e-learning, and in particular in distance learning, learners are required to have a much higher degree of self-control and environmental management, they must make a large number of independent decisions and play roles, which are performed by the teacher in the traditional form of education. The idea that students should be able to orient themselves in the learning situation determines a new status of the role of the teacher, who is already accepted as a consultant, providing methodological and psychological support. This changed role inspires in the learner a feeling of greater autonomy in the learning process itself, a liberation from stereotypes and a change in identification compared to traditional forms of learning.

The specifics of e-language learning provide means to meet the needs of learners, which in comparison with traditional learning, are consistent with the characteristics of modern e-society. At the same time, it reformulates the status and the role of the teacher and the learner within an online community working towards common educational goals. The completely distance form of e-learning has significant advantages: the learning materials, exercises, assignments, resources and tests are available to the learners without time limit and thus everyone can plan and carry out their own learning. At the same time, the tutor has an overview of the learning activities and can influence the pace of work, give instructions and answer inquiries. With motivated trainees and good infrastructure (Internet availability, quality connection, continuous operation of the server with the data of the e-course) effective training is achieved. A different situation is also possible: lack of access to the Internet, interruptions in the connection for technical reasons, or incorrect performance of tasks, exercises and tests by the trainees. In this case, the tutor has little opportunity to influence the learning process. Therefore, some of the activities that give the appearance of the given training course can be carried out in person, e.g. giving instructions for working with the electronic system for training, performing control tasks or attendance tests, guaranteeing the individual assessment of the trainees.

The Blended Learning combines the advantages of face-to-face learning and e-learning. Its aim is to combine the effectiveness of e-learning forms with socialization in traditional classroom teaching. Through the use of a combination of media, self-study modules, Internet resources and face-to-face learning, a flexible and attractive learning environment can be created. The e-learning module expands the possibilities 
of the course, including in addition to texts and photographs in the textbook and various audio, video and flash resources with an interactive nature. This makes learning more attractive and learners can practice according to their individual learning style. Didactic tests are a key tool for establishing the current level of foreign language proficiency according to the existing Council of Europe system. By comparing the results of a test in the classical form on paper and the results of a test generated by an e-learning system, it can be established to what extent the two types of testing give similar or different results. Replacing some of the conventional tests with web-based forms for testing students' knowledge is a significant competitive advantage for educational institutions. These new forms have not yet entered mass practice, as no sciencebased comparative analyses of conventional and web-based methods for testing and assessing knowledge have been made so far.

The innovative format has some undeniable advantages in a purely practical aspect, namely: 1 . It can save a significant resource of classroom employment and thus optimize the workload of the discipline "Foreign Language"; 2. Allows to accumulate a significant information resource (databases) that can be used repeatedly and provides structuring of a unique test for each learner; 3 . Saves a huge amount of extracurricular load of teachers (the time needed to check and evaluate conventional tests); 4. Ensures immediate access to the results while avoiding the time for checking and drawing up examination protocols; 5. Provides an opportunity for automation of the administrative procedures for entering the results in the student file, preparation of examination protocols, issuance of official and individual certificates, etc. 6. Can be used for effective current and final assessment in innovative forms of training (distance, part-time, semiattendance, optional, etc.). Therefore, E-learning provides for an opportunity for further development of teaching and mastering a specialized foreign language due to its flexibility, adaptability and motivating function. At higher levels of foreign language proficiency, a completely distance form of learning can be relied upon, while at lower levels the use of blended learning provides a richer toolkit for teaching and assessment.

\section{CONCLUSION}

Electronic foreign language learning with a business focus meets not only the higher needs of learners for self-improvement, but also their needs for self-esteem, respect and approval, as well as the need to belong to a social group and the needs for social contacts. The methodological and psychological support of the teacher should aim to support the identification of online learners as participants in a qualitatively different form of learning, developing their autonomy and integration motivation. Given its specifics, E-foreign language learning is a powerful tool for overcoming differentiation into heterogeneous groups of learners, while providing for opportunities for personal expression and communication in a foreign language through forms of synchronous and asynchronous communication (forums, e-mail, chat, video and audio conferencing, online group work). Due to the need to communicate through a tool that learners do not master perfectly, special attention should be paid to methods and techniques to encourage the reduction of language anxiety, especially at levels with a lower level of language competence. The BCom approach to social and economics science students has proved to be an excellent approach, which combines traditional education with E-learning content in conformity with the national strategies for development of the higher education sector (Terziev, 2020b, pp. 65-75). Thus a main conclusion that can be drawn from the conducted research is that business communication courses are a key element in the education of students in social sciences, based on the classic three pillars for a successful career - digital competence, foreign language skills and high competence in the subject areas studied in the bachelor's and master's degree programmes.

\section{ACKNOWLEDGEMENT}

This research was financially supported by the Academic Foundation "Prof. Dr. Minko Rousenov", Svishtov, Bulgaria (Grant No. 1001005) and the Institute of Scientific Research at D. A. Tsenov Academy of Economics, Svishtov, Bulgaria.

\section{REFERENCE LIST}

Common European Framework of Reference for Languages (CEFR). (2021, 5 10). Common European Framework of Reference for Languages: Learning, teaching, assessment. (C. o. Europe, Editor) Retrieved from https://www.coe.int/en/web/common-european-framework-reference-languages 
Diachok, N., Chernukha, N., Tokaruk, L., Udovenko, I., \& Petrova, M. (2020, August). Practical-oriented concept as a principle of professional education of the future professionals. International Journal of Higher Education(4), 272-282. doi:https://doi.org/10.5430/ijhe.v9n4p272

Elmubarak, M. (2020). AN ONLINE SEMI-STRUCTURED APPROACH TO HELPING STUDENTS MAKE THE MOST OF PROJECT-BASED LEARNING (PBL). IJAEDU-International E-Journal of Advances in Education, VI(18), 357-364. Retrieved from http://ijaedu.ocerintjournals.org/en/download/articlefile/1373889

Eurobarometar. (2021). Special Eurobarometer 386: Europeans and their Languages. Retrieved 0510 , 2021, from www.bit.ly/3yF6Kcl

Nenkov, N., Dyachenko, Y., Petrova, M., Bondarenko, G., \& Pustovit, V. (2017). Intelligent and Cognitive Technologies in Education of International Economic Relations Students and Human Resource Development in Enterprises: Methodology in Language. European Journal of Sustainable Development, 6(4), 353-360. doi:https://doi.org/10.14207/ejsd.2017.v6n4

Terziev, V. (2019). The role of business in society. Proceedings of SOCIOINT 2019, 6th International Conference on Education, Social Sciences and Humanities, 24-26 June 2019 (pp. 324-330). Istanbul, Turkey: International Organization Center of Academic Research.

Terziev, V. (2020b). New strategy for higher education for 2021-2030 in Bulgaria and challenges for its implementation. 60th International Scientific Conference on Economic and Social Development - XX International Social Congress (ISC 2020), 60, pp. 67-75. Moscow. Retrieved from https://www.researchgate.net/publication/345437242

Terziev, V., \& Ivanov, I. (2020). The national employment plan in Bulgaria - analysis and opportunities for change. International scientific journal „Internauka», Kiev, Ukraine, 15(95), 6-13.

Zagorodnya, A., Dichek, N., Chobitko, N., Voznyk, M., Honchar, L., \& Petrova, M. (2020, June). Professional training of the economic sector specialists at higher education institutions of the Republic of Poland and Ukraine: criteria of comparison. International Journal of Higher Education, 9(4), 139-144. doi:https://doi.org/10.5430/ijhe.v9n3p139

Zahariev, A. (2009). A New Impetus for Development of the Academic Thinking. Narodnostopanski Arhiv, LXII(International Edition), 5-7.

Zahariev, A., \& Zaharieva, G. (2003, September). HR management in Bulgarian firms - empirical evidences. Dialog(3), 5-36. doi:10.2139/ssrn.2977326 